\title{
Risks of PEG tube placement in patients with cirrhosis-associated ascites
}

This article was published in the following Dove Press journal:

Clinical and Experimental Gastroenterology

I September 2017

Number of times this article has been viewed

\section{Yasir Al-Abboodi' \\ Ali Ridha ${ }^{2}$ \\ Matthew Fasullo ${ }^{3}$ \\ Tarek H Naguib ${ }^{4}$}

'Internal Medicine Department, Saint Davis Round Rock Medical Centre, Round Rock, TX, USA, ${ }^{2}$ Internal Medicine Department, University of Arkansas for Medical Science, Little Rock, AR, USA, ${ }^{3}$ Internal Medicine Department, Umass Memorial Medical Center, Worcester, MA, USA, ${ }^{4}$ Internal Medicine Department, Texas Tech University Health and Sciences Center, Amarillo, TX, USA
Correspondence: Ali Ridha University of Arkansas for Medical Science, 430 I West Markham Street, Little Rock, AR 72205, USA

$\mathrm{Tel}+\mathrm{I} 979422563$ I

Fax + I 50I 6865609

Email alim.ridha@yahoo.com
Abstract: This study examined the safety of placing percutaneous endoscopic gastrostomy (PEG) tube in people with liver cirrhosis. The target population was further subdivided into people with ascites (case group) and people without ascites (control). We compare the morbidity and the mortality difference of PEG placement in cirrhotic patients with ascites vs cirrhotic patients without ascites. We then examined multiple factors including sex, race, chronic illness including hypertension, congestive heart failure, and others and their influence on the inpatient mortality of all cirrhotic patients who had PEG placement. A total of 38,175 inpatient PEG tube placements were identified. Only 583 patients out of 38,175 had a history of cirrhosis. One hundred seven had ascites and the rest did not. Mean age of the patients was 61.14 years. Patient demography included (65.2\%) male and the rest were female, 359 were white $(64.4 \%)$, 90 black $(14.8 \%)$, 84 Hispanic (13.7\%), 23 Asians (3.3\%), 7 Native Americans (0.4\%), and 20 others (3.5\%). Complications from PEG procedure in cirrhosis with ascites vs non-ascites included bleeding of $4(0.8 \%)$ vs $2(1.9 \%)(P=0.35)$, surgical site infection $2(0.4 \%)$ vs $1(0.9 \%)(P=0.51)$, and urinary tract infection $105(22.1 \%)$ vs $34(23.8 \%)(P=0.34)$, respectively. There was no colonic injury in either group. The total inpatient mortality was 75 out of the 583 . Fifty-six $(11.8 \%)$ were in the ascites group and $19(17.8 \%)$ in the non-ascites group $(P=0.097)$. Factors including ascites, postsurgical bleeding, and surgical site infection did not have influence on the inpatient mortality and there were no statistical differences between the two groups.

Keywords: percutaneous endoscopic gastrostomy, dysphagia, ascites, gastrointestinal

\section{Introduction}

Providing appropriate nutrition and medications can pose a significant challenge in the care of many patients who, for a myriad of reasons, cannot or will not eat. Enteralaccess procedures provide the short- and long-term option of providing nutrients and medications into the gastrointestinal tract for patients who cannot maintain adequate oral intake. Failure of enteral supplements, dietary counseling, and appetite stimulation frequently lead to a decision about the use of tube feeding. ${ }^{1}$ Percutaneous endoscopic gastrostomy (PEG) is one of the essential armaments to provide a means of feeding. As a relatively simple and safe procedure in experienced centers, it is commonly suggested to patients with swallowing disability seen in conditions such as stroke, Parkinson's disease, and in those with head and neck cancer. Also, it can be used in gastric decompression in patients with severe gastroparesis, malignant bowel obstruction, or chronic intestinal obstruction. ${ }^{2}$ There are possible complications of PEG such as wound infection, bleeding, necrotizing fasciitis, colocutaneous fistula, and death. ${ }^{3}$ 
Patients with liver cirrhosis usually end up with malnutrition because of loss of appetite, ${ }^{4}$ frequent hospitalizations, early satiety due to ascites, ${ }^{5}$ frequent paracentesis, altered mental status, fat- and lipid-soluble vitamins malabsorption due to bile acid depletion, ${ }^{6}$ bacterial overgrowth due to poor small intestine motility, pancreatic insufficiency, overzealous dietary restrictions, and medications such as diuretics and lactulose. ${ }^{7-10}$ Because of these aforementioned issues, nutrition and medication administration leads to an increased economic burden and negative health consequences.

Use of a PEG tube improves the nutritional status of cirrhotic patients and helps them to survive surgeries like liver transplant. ${ }^{11}$ Though, one of the relative contraindication to PEG tube placement is ascites owing to the concerns of ascitic fluid leakage. ${ }^{12}$ The following article will discuss the risk of the complications of PEG tube such as infection, bleeding, and mortality in patients with liver cirrhosis.

\section{Methods}

The 2009 National Inpatient Sample (NIS) was used. The NIS is the largest all-payer inpatient care database containing around 8 million hospital stays from about 1,000 hospitals in the USA. These data are collected as part of the Healthcare Cost and Utilization Project by the Agency for Healthcare Research and Quality. The NIS is designed to approximate a $20 \%$ sample of US nonfederal hospitals, including public hospitals and academic medical centers assigned by the American Hospital Association.

Each hospital record includes a unique patient identifier, demographic data, admission type, primary and secondary diagnosis and procedures, primary and secondary insurance payers, length of stay including hospital charges, and hospital characteristics. Hospital geographic region is subcategorized into Northeast, Midwest, West, and South. The control/ ownership of the hospitals is classified as government nonfederal (public), private not-for-profit (voluntary), and private investor-owned (proprietary).

\section{Case and outcome variable identifications}

The Clinical Modification of the International Classification of Diseases, Ninth Revision (ICD-9) diagnostic codes were used to capture all admissions in the NIS dataset with the primary diagnosis of liver cirrhosis (5718). The following ICD-9 codes were also used: PEG tube placement (4311), ascites $(789,51,78,959)$, postoperative bleeding (998.11), surgical site infection $(99,859)$, urinary tract infection (UTI) (5990), and colonic injury (86,350). Other variables used in this study have already been identified in the NIS data, for instance, race, congestive heart failure, hypertension, and obesity.

\section{Statistical analysis}

The target population is cirrhotic patients who underwent PEG procedure. The target population was further subdivided into people with ascites and people without ascites.

The primary outcome of the study is examining the morbidity and the mortality difference of PEG placement in cirrhotic patients with ascites and cirrhotic patients without ascites. We then examined multiple factors including sex, race, chronic illness including hypertension, congestive heart failure, and obesity and their influence on the inpatient mortality of all cirrhotic patients who underwent PEG placement.

Data were analyzed using the IBM SPSS version 24 statistical software for Mac computer. Mean, percentages, and standard deviation of the mean were used to examine the demographic feature of the target population. Multivariate logistic regression statistical test is used to compare the mortality and morbidity difference between these two groups. A CI of $95 \%$ and $P$ value $<0.05$ were determined to define the statistical difference between the two groups.

\section{Results}

A total of 38,175 of inpatient PEG tube placements were identified using ICD-9 code within the NIS database. Only 583 patients out of 38,175 had a history of cirrhosis. One hundred seven had ascites and the rest were without ascites. Mean age of the patient was 61.14 years.

Patients demography included (65.2\%) male and the rest were female, 359 were white (64.4\%), 90 black (14.8\%), 84 Hispanic (13.7\%), 23 Asians (3.3\%), 7 Native Americans $(0.4 \%)$, and 20 others $(3.5 \%)$ (Table 1$)$.

The complications from PEG procedure in cirrhosis with ascites vs non-ascites included bleeding of $4(0.8 \%)$ vs

Table I Target population demography

\begin{tabular}{ll}
\hline Demographic & Percentage \\
\hline Age, years, mean & 61.14 \\
Sex, $\mathbf{n}(\%)$ & \\
Male & $380(65.2)$ \\
Female & $203(34.8)$ \\
Race, $\mathbf{n}(\%)$ & \\
White & $359(64.4)$ \\
African American & $90(14.8)$ \\
Hispanic & $84(13.7)$ \\
Asian & $23(3.3)$ \\
Native American & $7(0.4)$ \\
Other & $20(3.5)$ \\
Mean length of stay in days & 15.84 \\
\hline
\end{tabular}


$2(1.9 \%)(P=0.35$, odds ratio $[\mathrm{OR}]=2.24,95 \% \mathrm{CI} 04-12.34)$, surgical site infection of $2(0.4 \%)$ vs $1(0.9 \%)(P=0.51$, $\mathrm{OR}=2.23,95 \%$ CI $0.2-2.4)$, and UTI of $105(22.1 \%)$ vs 34 (23.8\%) $(P=0.34$, OR 1.6, 95\% CI 1.03-2.6). There was no colonic injury in either group. The total inpatient mortality was 75 out of the 583. Fifty-six (11.8\%) in the ascites group vs $19(17.8 \%)$ in the non-ascites $(P=0.097$, OR $1.5,95 \% \mathrm{CI}$ 0.9-2.8) (Table 2).

Multiple factors including ascites, postsurgical bleeding, surgical site infection, UTI, sex, race congestive heart failure, chronic lung disease, diabetes, hypertension, and obesity were examined to see if there was any influence on the inpatient mortality. None of the factors mentioned above were of statistically significant risk (Table 3 ).

\section{Discussion}

Over the last two decades, the use of enteral feeding interventions has become an increasingly popular modality for administering nutrition and medications in patients who are unable to consume by mouth for a variety of reasons. ${ }^{13}$ Although PEG placement is technically simple to perform, it has a general complication rate of up to $50 \%$ and major complications occur in up to $7 \%$ of cases. Commonly reported complications after PEG include wound infection, aspiration pneumonia, UTI, and bleeding. ${ }^{14,15}$ Several prior studies have demonstrated low albumin levels, high C-reactive protein levels, advanced age, low body mass index, and multiple comorbidities as potential risk factors for increased mortality and complication rates of PEG placement. ${ }^{16,17}$

Very limited data exist today regarding PEG tube placement in a cirrhotic patient. Few small case series have displayed mortality and complication rates among this patient population but with mixed results. One commonly encountered issue in a cirrhotic patient is the risk of performing a PEG placement in the setting of ascites. To date this study represents the largest number $(n=107)$ of cirrhotic patients with ascites undergoing PEG tube placement to better risk stratify which risk factors lead to poor clinical outcomes. Even as early as a decade ago, ascites was cited to be an absolute contraindication to PEG placement because of the believed increased risk for developing peritonitis. ${ }^{18}$ According to a case series study, the overall mortality of patients with cirrhosis who underwent PEG might reach $38 \%-42 \% .{ }^{11}$ Nine of the 10 patients who died in the first 30 days had ascites at the time of PEG tube placement. Two patients died as a direct consequence of complications from the PEG procedure, whereas the other deaths were related to progression of liver disease or factors not directly related to the PEG. The authors in the above study did not compare cirrhotic patients with ascites vs cirrhotic patients without ascites, and they made an assumption that ascites is an independent risk factor while their result was only describing the percentage of the people who died. In our study, the number of people who died in the cirrhosis with ascites group was 19 vs 56 in the cirrhosis non-ascites group. Although cirrhotic patients with ascites had an adjusted OR of 1.6 of being more likely to die during hospitalization than people without ascites, this was not statistically significant as the $P$ value was $>0.05$ ( $P$ value 0.115 and $95 \%$ CI $0.89-2.86$ ).

Our finding could be different for several potential reasons from previous studies that showed ascites as an independent risk factor. One of the reasons is that the national inpatient data unfortunately lack the Model for End-Stage Liver Disease (MELD) or Child-Pugh score, which has an influence on the mortality statistics of people with liver cirrhosis, and people in our target population might have a different lower MELD score than the target population in previous studies. The amount of ascites also cannot be assessed in this data, which could also have an effect on the procedure outcome.

Table 3 Risk factor and inpatient mortality

\begin{tabular}{llll}
\hline Condition & $\boldsymbol{P}$-value & Odds ratio & $\mathbf{9 5 \%} \mathbf{C l}$ \\
\hline Esophageal varices & 0.97 & 1.02 & $0.29-3.53$ \\
Ascites & 0.115 & 1.5 & $0.89-2.86$ \\
Sex & 0.496 & 0.83 & $0.48-1.41$ \\
Race & 0.002 & 0.145 & $0.9-1.67$ \\
Congestive heart failure & 0.097 & 1.67 & $0.911-3.08$ \\
Lung disease & 0.353 & 1.3 & $0.748-2.25$ \\
Diabetes mellitus & 0.138 & 1.5 & $0.87-2.67$ \\
Hypertension & 0.085 & 0.6 & $0.38-1.06$ \\
Obese & 0.411 & 1.4 & $0.61-3.25$ \\
Urinary tract infection & 0.769 & 1.0 & $0.60-1.95$ \\
Postoperative bleeding & 0.289 & 2.5 & $0.45-14.2$ \\
Surgical site infection & 0.941 & 0.9 & $0.09-5.80$ \\
\hline
\end{tabular}

Table 2 Complication from percutaneous endoscopic gastrostomy tube placement

\begin{tabular}{|l|l|l|l|l|l|}
\hline Complication & \multicolumn{2}{|c|}{ Ascitis I07 vs non-ascitis 476 } & P-value & Odds ratio & 95\% Cl \\
\hline Postoperative bleeding & $4(0.8 \%)$ & $2(1.9 \%)$ & 0.35 & 2.244 & $0.45-12.3$ \\
Surgical site infection & $2(0.4 \%)$ & $1(0.9 \%)$ & $0.5 \mathrm{I}$ & 2.23 & $0.2-2.4$ \\
Urinary tract infection & $105(22.1 \%)$ & $34(23.8 \%)$ & 0.34 & 1.6 & $1.03-2.6$ \\
Colonic injury & 0.00 & 0.00 & & & \\
\hline
\end{tabular}


Our study had certain limitations in that the NIS is a retrospective database using administrative ICD-9 codes, thus questioning the accuracy of coding procedures. It also does not have information about the specific technique used in a procedure. NIS is unable to display readmission rates; therefore, the mortality rate could be underestimated in the given patient population. NIS data are unable to identify the main cause of death as the database includes only general inpatient mortality. Our data does not include the outpatient encounters, which could introduce selection bias. Finally, there could also be a clerical error involved as the database is taken from charts completed by humans, with human error, as well as completion of charts from many different institutions across the USA. While several limitations may exist, we believe that these are counterbalanced by the large sample size and absence of reporting bias as evident in some publications from specialized centers or those with a financial interest.

\section{Conclusion}

Our study showed by using the largest sample of patients so far, that PEG placement in cirrhosis patients with ascites has a higher mortality rate than non-cirrhotics but they were not statistically different.

\section{Disclosure}

The authors report no conflicts of interest in this work.

\section{References}

1. Lockett MA, Templeton ML, Byrne TK, Norcross ED. Percutaneous endoscopic gastrostomy complications in a tertiary-care center. Am Surg. 2002;68(2):117-120.

2. Delegge MH. Nutrition in Gastrointestinal Disease. In: Feldman M, Friedman LS, Brandt LJ ed. Feldman: Sleisenger and Fordtran's Gastrointestinal and Liver Disease. 9th ed. Philadelphia, PA: Saunders Elsevier; 2010:277-297.
3. Schneider AS, Schettler A, Markowski A, et al. Complication and mortality rate after percutaneous endoscopic gastrostomy are low and indication-dependent. Scand J Gastroenterol. 2014;49(7):891-898.

4. Testa R, Franceschini R, Giannini E, et al. Serum leptin levels in patients with viral chronic hepatitis or liver cirrhosis. J Hepatol. 2000;33(1): 33-37.

5. Galati JS, Holdeman KP, Dalrymple GV, Harrison KA, Quigley EM. Delayed gastric emptying of both the liquid and solid components of a meal in chronic liver disease. Am J Gastroenterol. 1994;89(5):708-712.

6. Phillips JR, Angulo P, Petterson T, Lindor KD. Fat-soluble vitamin levels in patients with primary biliary cirrhosis. Am J Gastroenterol. 2001;96(9):2745-2750.

7. Bauer TM, Steinbruckner B, Brinkmann FE, et al. Small intestinal bacterial overgrowth in patients with cirrhosis: prevalence and relation with spontaneous bacterial peritonitis. Am J Gastroenterol. 2001;96(10):2962-2967.

8. DiMagno EP, Go VL, Summerskill WH. Relations between pancreatic enzyme ouputs and malabsorption in severe pancreatic insufficiency. N Engl J Med. 1973;288(16):813-815.

9. Berne Y, Carias D, Cioccia AM, Gonzalez E, Hevia P. Effect of the diuretic furosemide on urinary essential nutrient loss and on body stores in growing rats. Arch Latinoam Nutr. 2005;55(2):154-160.

10. Seki N, Hamano H, Iiyama Y, et al. Effect of lactulose on calcium and magnesium absorption: a study using stable isotopes in adult men. J Nutr Sci Vitaminol (Tokyo). 2007;53(1):5-12.

11. Baltz JG, Argo CK, Al-Osaimi AM, Northup PG. Mortality after percutaneous endoscopic gastrostomy in patients with cirrhosis: a case series. Gastrointest Endosc. 2010;72(5):1072-1075.

12. Rahnemai-Azar AA, Rahnemaiazar AA, Naghshizadian R, Kurtz A, Farkas DT. Percutaneous endoscopic gastrostomy: indications, technique, complications and management. World J Gastroenterol. 2014;20(24):7739-7751.

13. Safadi BY, Marks JM, Ponsky JL. Percutaneous endoscopic gastrostomy. Gastrointest Endosc Clin NAm. 1998;8:551-568.

14. Mamel JJ. Percutaneous endoscopic gastrostomy. Am J Gastroenterol. 1989;84:703-710.

15. Grant DG, Bradley PT, Pothier DD, et al. Complications following gastrostomy tube insertion in patients with head and neck cancer: a prospective multi-institution study, systematic review and meta-analysis. Clin Otolaryngol. 2009;34(2):103-112.

16. Lang A, Bardan E, Chowers Y, et al. Risk factors for mortality in patients undergoing percutaneous endoscopic gastrostomy. Endoscopy. 2004;36(6):522-526

17. Figueiredo FA, da Costa MC, Pelosi AD, Martins RN, Machado L, Francioni E. Predicting outcomes and complications of percutaneous endoscopic gastrostomy. Endoscopy. 2007;39(4):333-338.

18. Yarze JC. Peritonitis after PEG placement in patients with cirrhotic ascites. Gastrointest Endosc. 2011;73(5):1071.
Clinical and Experimental Gastroenterology

\section{Publish your work in this journal}

Clinical and Experimental Gastroenterology is an international, peerreviewed, open access, online journal publishing original research, reports, editorials, reviews and commentaries on all aspects of gastroenterology in the clinic and laboratory. This journal is included on PubMed. The manuscript management system is completely online

\section{Dovepress}

and includes a very quick and fair peer-review system, which is all easy to use. Visit http://www.dovepress.com/testimonials.php to read real quotes from published authors. 